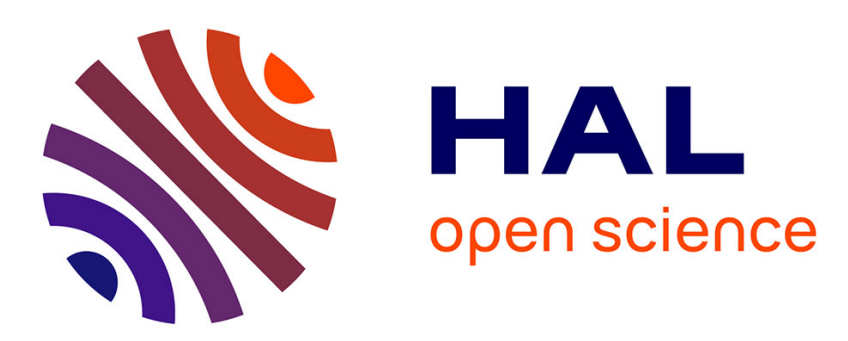

\title{
Thermally driven asymmetric responses of grains versus spin-glass related distributions of blocking temperature in exchange biased Co/IrMn bilayers
}

Vincent Baltz

\section{- To cite this version:}

Vincent Baltz. Thermally driven asymmetric responses of grains versus spin-glass related distributions of blocking temperature in exchange biased Co/IrMn bilayers. Applied Physics Letters, 2013, 102, pp.062410. 10.1063/1.4792347 . hal-01683658

\section{HAL Id: hal-01683658 https://hal.science/hal-01683658}

Submitted on 19 May 2019

HAL is a multi-disciplinary open access archive for the deposit and dissemination of scientific research documents, whether they are published or not. The documents may come from teaching and research institutions in France or abroad, or from public or private research centers.
L'archive ouverte pluridisciplinaire HAL, est destinée au dépôt et à la diffusion de documents scientifiques de niveau recherche, publiés ou non, émanant des établissements d'enseignement et de recherche français ou étrangers, des laboratoires publics ou privés. 


\title{
Thermally driven asymmetric responses of grains versus spin-glass related distributions of blocking temperature in exchange biased Co/IrMn bilayers
}

\author{
V. Baltz ${ }^{a}$ \\ SPINTEC, UMR 8191 CNRS/INAC-CEA/UJF-Grenoble 1/Grenoble-INP, F-38054 Cedex, France
}

(Received 20 November 2012; accepted 1 February 2013; published online 13 February 2013)

\begin{abstract}
Controlling ferromagnetic/antiferromagnetic blocking temperatures in exchange biased based devices appears crucial for applications. The blocking temperature is ascribed to the ability of both antiferromagnetic grains and interfacial spin-glass-like phases to withstand ferromagnetic magnetization reversal. To better understand the respective contributions of grains versus spin-glass, blocking temperature distributions were measured after various thermal treatments for cobalt/iridium-manganese bilayers. The high-temperature contribution linked to antiferromagnetic grains shifts towards lower temperatures above a threshold thermal annealing. In contrast, the occurrence and evolution of training effects for the low-temperature contribution only agree with its inferred interfacial spin-glass-like origin. (c) 2013 American Institute of Physics. [http://dx.doi.org/10.1063/1.4792347]
\end{abstract}

Exchange bias (EB) refers to the exchange coupling between a ferromagnet $(\mathrm{F})$ and an antiferromagnet $(\mathrm{AF})^{1,2}$ and defines the reference direction required for the spin of conduction electrons in spintronics applications such as magnetic random access memories (MRAMs), sensors, logic devices, and radiofrequency emitters. ${ }^{3}$ In addition to that, thermally assisted (TA) MRAMs use EB in order to store data at room temperature $(\mathrm{T})$ and to write binary data by elevation of $\mathrm{T}$ above the blocking temperature $\left(\mathrm{T}_{\mathrm{B}}\right)$ and subsequent cooling with either positive or negative induced field. It is thereby essential to fully understand the EB phenomenon and in particular $\mathrm{T}_{\mathrm{B}}$ and their dispersions $\left(\mathrm{DT}_{\mathrm{B}}\right)$ for TA-MRAM applications. Since the first study on $\mathrm{EB},{ }^{4}$ most authors now agree that, for F/AF thin films, EB is ascribed to the ability of both AF grains (domains) $)^{5-12}$ and AF interfacial spin-glass-like phases ${ }^{8-18}$ to withstand $\mathrm{F}$ magnetization reversal. Although a substantial number of works have been reported, the respective contributions of grains versus interfacial spin-glass are still controversial and the concomitant mastering of the effect is still partial. It would become less so by systematically carrying out simultaneous observations, hitherto rarely completed. ${ }^{9-12}$ The specific procedure commonly carried out for measurements of $\mathrm{DT}_{\mathrm{B}}$ above $300 \mathrm{~K}$ combined with the alternative use of a sufficiently low reference $\mathrm{T}$ recently provided a method for the above purpose. The present study focuses on the responses of the $\mathrm{DT}_{\mathrm{B}}$ contributions to gradual annealing, which are expected to modify the layers properties above a threshold T. ${ }^{19,20}$ Owing to the various origins presumed for the two contributions to $\mathrm{DT}_{\mathrm{B}}$ : grains versus interfacial spin-glass, distinct responses are expected, thereby possibly supporting their different causes and providing an additional knob for their respective understanding and control.

In this work, $\mathrm{Ta}(3 \mathrm{~nm}) / \mathrm{Cu}(3 \mathrm{~nm}) / \mathrm{Co}(3 \mathrm{~nm}) / \mathrm{IrMn}(7 \mathrm{~nm}) /$ $\operatorname{Pt}(2 \mathrm{~nm})$ are sequentially deposited at room-T by DCmagnetron sputtering onto a thermally oxidised silicon substrate. ${ }^{9}$ IrMn is made from an $\mathrm{Ir}_{20} \mathrm{Mn}_{80}$ target. A static

${ }^{\text {a)} E l e c t r o n i c ~ m a i l: ~ v i n c e n t . b a l t z @ c e a . f r . ~}$ positive magnetic field of $2.5 \mathrm{kOe}$ is applied in the sample plane during the entire deposition process. It is large enough to saturate the magnetization of the Co layer during the deposition of the IrMn layer. Therefore, all the growing AF entities with $T_{B}$ higher than the deposition- $T$ orient toward the positive direction. ${ }^{9}$ Applying a field $a b$ initio does not require post-deposition field cooling (FC) to set $\mathrm{EB}$, so it provides a reference as-deposited sample. After deposition, the sample is cut up into pieces subject to a positive FC from an initial annealing temperature $\left(\mathrm{T}_{\text {init }}\right)$ down to $4 \mathrm{~K}$. The field $\left(\mathrm{H}_{\mathrm{FC}}\right)$ applied during cooling stands along the direction of the $a b$ initio field and, similarly, is large enough to saturate the Co layer. For the various sample pieces, $\mathrm{T}_{\text {init }}$ is respectively equal to 300 (i.e., no post-deposition annealing), $450,550,650$, and $750 \mathrm{~K}$. Following the initial FC, $\mathrm{DT}_{\mathrm{B}}$ in the range of $4 \mathrm{~K}$ to $\mathrm{T}_{\text {init }}$ is deduced from hysteresis loops measured with a superconducting quantum interference device (SQUID). All the loops are performed at $4 \mathrm{~K}$ after a specific procedure, which involves FC from incremental annealing temperatures $\left(\mathrm{T}_{\mathrm{a}}\right)^{7,9}$ Since the $\mathrm{T}$ in the SQUID can only reach $400 \mathrm{~K}$, for $\mathrm{T}_{\text {init }}$ and $\mathrm{T}_{\mathrm{a}}$ larger than $400 \mathrm{~K}$, the samples are first $\mathrm{FC}$ in a furnace from $\mathrm{T}_{\text {init }}\left(\mathrm{T}_{\mathrm{a}}\right)$ down to room-T and then FC in the SQUID from 300 to $4 \mathrm{~K}$. Since room- $\mathrm{T}$ was not exceeding $300 \mathrm{~K}$ during the experimental period, any effect of a minor loop due to the zero field transfer at room- $T$ is expected to be reset when cooling from 300 to $4 \mathrm{~K}$ in the SQUID.

Typical hysteresis loops are shown in Fig. 1 for $\mathrm{T}_{\text {init }}=550 \mathrm{~K}$. After initial positive $\mathrm{FC}$ from $\mathrm{T}_{\text {init }}$ to $4 \mathrm{~K}$, all the AF entities contributing to $\mathrm{EB}$ orient toward the positive direction. This leads to maximum loop shift for $\mathrm{T}_{\mathrm{a}}=4 \mathrm{~K}$. From this initial state, the procedure consists in gradually reorienting the $\mathrm{AF}$ entities by use of negative $\mathrm{FC}$ down to $4 \mathrm{~K}$ from incremental $\mathrm{T}_{\mathrm{a}} \cdot{ }^{7,9}$ The AF entities with $\mathrm{T}_{\mathrm{B}}$ lower than $T_{a}$ reverse. After each increment of $T_{a}$, a loop is measured at $4 \mathrm{~K}$. Its shift in field $\left(\mathrm{H}_{\mathrm{E}}\right)$ is proportional to the difference between pinned AF entities oriented positively and negatively. A gradual change in the amplitude and sign of $\mathrm{H}_{\mathrm{E}}$ is observed in Fig. 1, since the higher the $\mathrm{T}_{\mathrm{a}}$, the more 

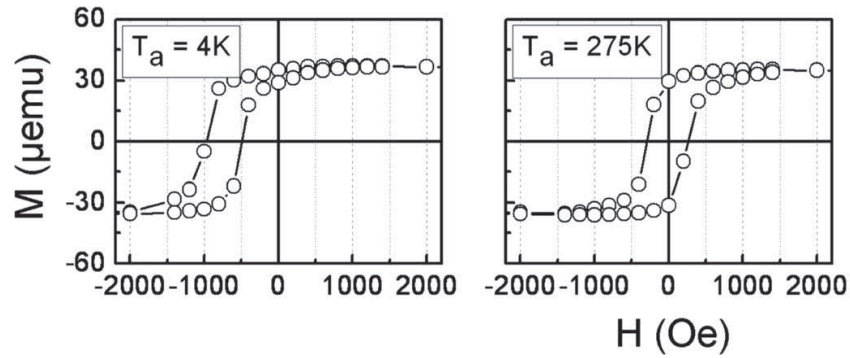

FIG. 1. Typical hysteresis loops measured at $4 \mathrm{~K}$ by SQUID along the FC direction, for a film of $\mathrm{Ta}(3 \mathrm{~nm}) / \mathrm{Cu}(3 \mathrm{~nm}) /$ $\mathrm{Co}(3 \mathrm{~nm}) / \operatorname{IrMn}(7 \mathrm{~nm}) / \mathrm{Pt}(2 \mathrm{~nm})$ subject to a procedure detailed within the text and involving various annealing temperatures $\left(\mathrm{T}_{\mathrm{a}}\right)$. reversed entities. $\mathrm{H}_{\mathrm{E}}$ recovers its maximum around the maximum $\mathrm{T}_{\mathrm{B}}$, here $450 \mathrm{~K}$, but with opposite sign, as a result of the reorientation of all the $\mathrm{AF}$ entities.

The variations of coercivity, $\mathrm{H}_{\mathrm{C}}$ and loop shift, $\mathrm{H}_{\mathrm{E}}$ with $\mathrm{T}_{\mathrm{a}}$ are plotted in Fig. 2 for the various $\mathrm{T}_{\text {init }}$. For some $\mathrm{T}_{\mathrm{a}}$, hysteresis loops are measured few consecutive times to probe potential training effects. ${ }^{21,22}$ To ease the reading, the concomitant data points are only plotted when relevant, i.e., when $\mathrm{H}_{\mathrm{E}}$ and $\mathrm{H}_{\mathrm{C}}$ vary from loop number $n$ to $n+1$. Although it is accepted that training effects are triggered by $\mathrm{F}$ cycling and refer to the macroscopic signature of the rearrangement of the $\mathrm{AF}$ spin configuration toward equilibrium, the underlying microscopic mechanisms may be diverse. The effect has usually been considered as a rearrangement of $\mathrm{AF}$

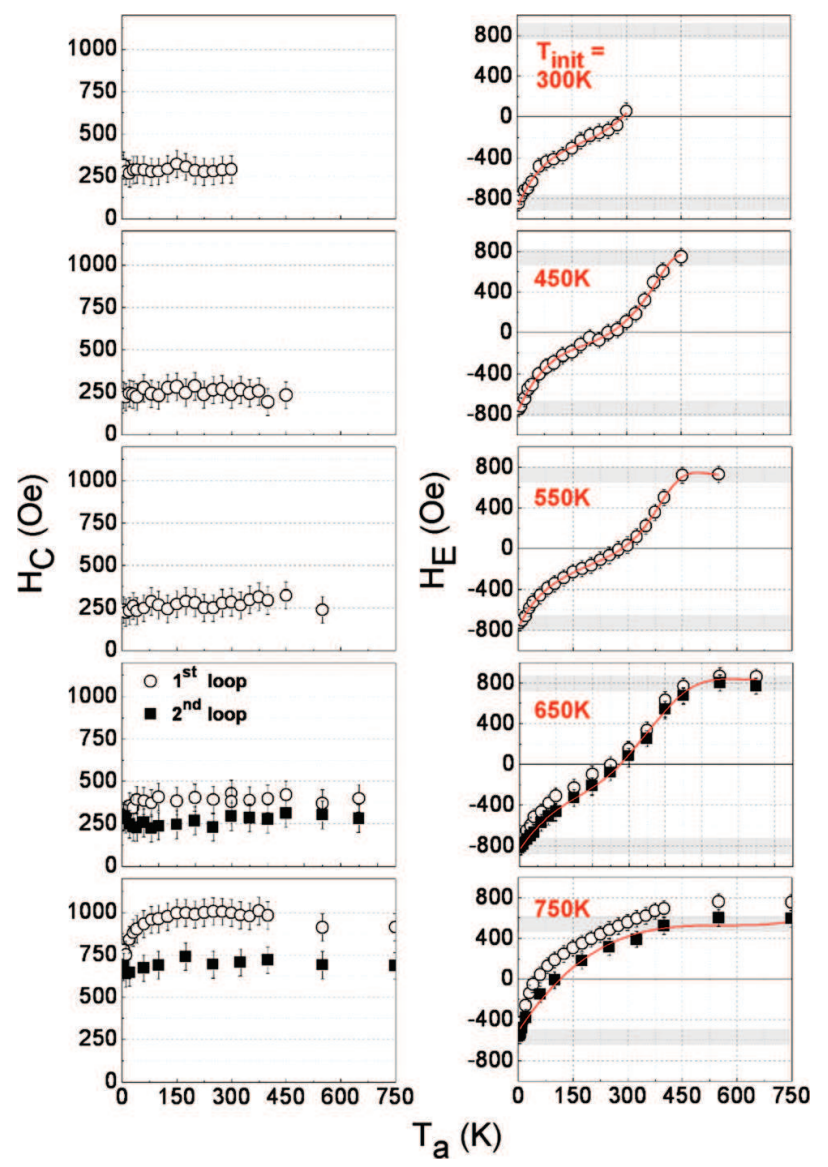

FIG. 2. Variations with $T_{a}$ of the coercive field $\left(H_{C}\right)$ and loop shift $\left(H_{E}\right)$ deduced from hysteresis loops measured at $4 \mathrm{~K}$ (Fig. 1) for pieces of the same film subject to various initial temperatures $\left(T_{\text {init }}\right)$. The notations 1 st and 2 nd refer to consecutive loops recorded at $4 \mathrm{~K}$. The full lines result from interpolation of the data. The grey areas represent, within the experimental error, the minimum value of $\mathrm{H}_{\mathrm{E}}\left(\mathrm{H}_{\mathrm{E}, \mathrm{min}}\right)$ determined experimentally and the expected maximum value $\left(\mathrm{H}_{\mathrm{E}, \max }\right)$ calculated from: $\mathrm{H}_{\mathrm{E}, \max }=-\mathrm{H}_{\mathrm{E}, \min }$. domains $^{16,21}$ and could be derived in a phenomenological description that considers an associated order parameter for the AF interfacial magnetization. ${ }^{23}$ The above descriptions lead to a square root decrease of $\mathrm{H}_{\mathrm{E}}$ with $n$. Alternatively, some studies have shown that the sole AF symmetry could account for rearrangements. ${ }^{16,21}$ In this latter picture, symmetry induced training effects vanish after two loops, but "usual" training may take over afterwards. ${ }^{16}$ Here, from Fig. 2, no training was observed for $\mathrm{T}_{\text {init }} \leq 550 \mathrm{~K}$. In contrast, for higher $\mathrm{T}_{\text {init }}(650$ and $750 \mathrm{~K})$, the differences between $1 \mathrm{st}$ and 2nd loops-see Fig. 3(a)—clearly highlight training. Figure 2 also shows that, for $\mathrm{T}_{\text {init }} \leq 550 \mathrm{~K}$ and within the experimental error, $\mathrm{H}_{\mathrm{C}}$ is independent of $\mathrm{T}_{\mathrm{a}}$. This is expected since all the loops are measured at the same T. However, for $\mathrm{T}_{\text {init }} \geq 650 \mathrm{~K}$, due to training as detailed below, the 1 st loop $\mathrm{H}_{\mathrm{C}}$ increases up to $\mathrm{T}_{\mathrm{a}} \sim 75 \mathrm{~K}$ and then levels out. After the 2nd loop, $\mathrm{H}_{\mathrm{C}}$ recovers its independence on $\mathrm{T}_{\mathrm{a}}$, which indicates that training has vanished. This agrees with the fact that no training was observed for further loops. As a consequence of the dissimilar variations of $\mathrm{H}_{\mathrm{C}}$ with $\mathrm{T}_{\mathrm{a}}$ for the $1 \mathrm{st}$ and 2 nd loops, the difference between the two increases when $T_{a}$ raises and then levels out at $\sim 75 \mathrm{~K}$, see Fig. 3(b). As also shown in Fig. 3(b), $\mathrm{H}_{\mathrm{E}}$ shows similar trends. Training effects thus seem to be related here to anything that responds at low-T. Taking into account the presumed AF interfacial spin-glass-like origin of the low-T contribution to $\mathrm{DT}_{\mathrm{B}},{ }^{9,13}$ the following scenario can be suggested. First, when $\mathrm{T}_{\mathrm{a}}$ increases, there is a rise of the amount of AF interfacial spin-glass phases sensitive to training and dragged along during the first $\mathrm{F}$ cycling, since more spinglasses with $\mathrm{T}_{\mathrm{B}}$ comprised between $4 \mathrm{~K}$ and $\mathrm{T}_{\mathrm{a}}$ are reversed. In accordance with the training effect phenomenological picture, ${ }^{16,21-23}$ these spins are probably initially in a high energy metastable state. Then, training levels out when $\mathrm{T}_{\mathrm{a}}$ reaches the spin-glasses maximum $\mathrm{T}_{\mathrm{B}}$, i.e., beyond the low- $\mathrm{T}$ contribution to $\mathrm{DT}_{\mathrm{B}}$. In accordance, the spin-glass maximum $\mathrm{T}_{\mathrm{B}}$ corresponds to around $75 \mathrm{~K}$, as can be seen in Fig. 4(b). Finally, above the spin-glass maximum $\mathrm{T}_{\mathrm{B}}$, the amount of spin-glass contributing to training is maximum, since all the spin-glasses subject to being dragged are then involved whatever $T_{a}$. When $T_{a}$ reaches higher $T$ it comes to additionally repining $\mathrm{AF}$ spins of full grains due to the granular origin of the high-T contribution to $\mathrm{DT}_{\mathrm{B}}$. The AF grains here certainly stand in a more stable repined magnetic configuration less prone to training since another increase in training is not observed. The fact that training occurs above $\mathrm{T}_{\text {init }}=650 \mathrm{~K}$ means that the spin-glass phases became more sensitive to reorientation as a likely consequence of thermally activated intermixing and subsequent modifications of some layers properties. ${ }^{19,20}$ 
(a)

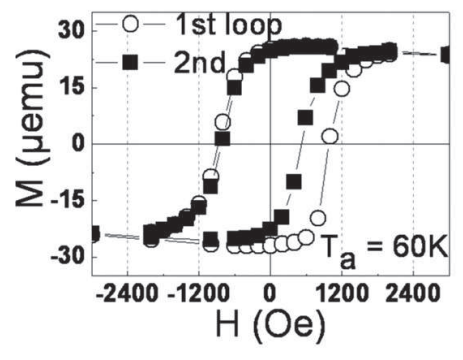

(b)

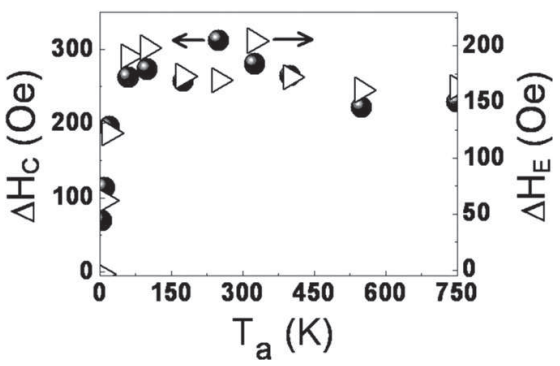

FIG. 3. For $\mathrm{T}_{\text {init }}=750 \mathrm{~K}$ : (a) two successive hysteresis loops for $\mathrm{T}_{\mathrm{a}}=60 \mathrm{~K}$ and $(\mathrm{b})$ variations with $\mathrm{T}_{\mathrm{a}}$ of the differences of $\mathrm{H}_{\mathrm{C}}$ and of $\mathrm{H}_{\mathrm{E}}$ between 1st and 2nd loops.
Back to the mechanism at the origin of training: an isolated spin-glass-like phase shows no symmetry and therefore is not prone to training induced by symmetry. ${ }^{16,22}$ With that regards and taking into account that $\mathrm{H}_{\mathrm{E}}$ vanishes here after two loops, it might well be that the origin of training is the "usual" thermal training discussed further up, which dies off quickly notably because the $T_{B}$ of these spin-glasses is small compared to the measurement $\mathrm{T}$ of $4 \mathrm{~K} .{ }^{24}$ In addition, despite the inherent random and thus isotropic character of an isolated spin-glass, the coupling to the AF spin lattice underneath for F/AF systems likely brings anisotropy and preferential axes, thus lowering the energy of some arrangements of the spin-glass-like phase. Training induced by the AF symmetry and which is characteristic of a training that vanishes after two loops may be an alternative explanation. Let me then develop this in the framework of the model suggested in Ref. 22 for biaxial anisotropy AF like IrMn: some initially noncollinear $\left(\sim 90^{\circ}\right)$ AF spins relax into an energetically more favourable collinear and antiparallel arrangement $\left(\sim 180^{\circ}\right)$ after the first $\mathrm{F}$ reversal. For a field applied at an angle $\phi$ from one of the AF easy axes, the condition for training, i.e., the condition for initial $\sim 90^{\circ}$ arrangement of AF spins as opposed to initial antiparallel alignment and no training otherwise, is given by the following equation: ${ }^{22}$

$$
\left|\frac{\mathrm{J}_{\mathrm{F}-\mathrm{AF}}+\varepsilon_{\mathrm{FC}}}{\mathrm{J}_{\mathrm{AF}}} \cdot \frac{\mathrm{M}_{\mathrm{F}}}{\mathrm{M}_{\mathrm{AF}}} \cdot \frac{\mathrm{t}_{\mathrm{F}}}{\mathrm{t}_{\mathrm{AF}}}\right|>\frac{1}{\cos (\phi)+\sin (\phi)}
$$

where $\mathrm{J}_{\mathrm{F}-\mathrm{AF}}$ is the interfacial exchange energy per unit surface between $\mathrm{F}$ and $\mathrm{AF}$ spins, $\mathrm{J}_{\mathrm{AF}}$ is the exchange energy per unit surface between $\mathrm{AF}$ spins, $\mathrm{M}_{\mathrm{F}}$ and $\mathrm{M}_{\mathrm{AF}}$ are the respective magnetizations per unit volume of the sublattices, $t_{\mathrm{F}}$ and $t_{\mathrm{AF}}$ are the respective thicknesses, and $\varepsilon_{\mathrm{FC}}$ is the Zeeman energy per unit surface during $\mathrm{FC}: \varepsilon_{\mathrm{FC}}=\mathrm{H}_{\mathrm{FC}} \cdot \mathrm{M}_{\mathrm{F}} \cdot \mathrm{t}_{\mathrm{F}}$. The grains show no training thus Eq. (1) is in all likelihood not fulfilled, since
$\mathrm{t}_{\mathrm{AF}}$ is probably too large. Instead, interfacial AF spin-glass phases could fulfil Eq. (1), due to their smaller effective thicknesses. The fact that training only occurs above $\mathrm{T}_{\text {init }}=650 \mathrm{~K}$, means that Eq. (1) then becomes fulfilled. More specifically, for high $\mathrm{T}_{\text {init }}$, the ratio $\left(\mathrm{J}_{\mathrm{F}-\mathrm{AF}}+\mathrm{H}_{\mathrm{FC}} \cdot \mathrm{M}_{\mathrm{F}} \cdot \mathrm{t}_{\mathrm{F}}\right) \cdot \mathrm{M}_{\mathrm{F}} \cdot \mathrm{t}_{\mathrm{F}} /$ $\left(\mathrm{J}_{\mathrm{AF}} \cdot \mathrm{M}_{\mathrm{AF}} \cdot \mathrm{t}_{\mathrm{AF}}\right)$ increases, as a likely consequence of thermally activated layers intermixing. ${ }^{19,20}$ Although definite values of $\mathrm{J}_{\mathrm{F}-\mathrm{AF}}, \mathrm{J}_{\mathrm{AF}}$, and $\mathrm{M}_{\mathrm{AF}}$ are not straightforwardly accessible to experiments, the other values can be measured and trends can then be assessed. $\mathrm{H}_{\mathrm{FC}}$ stays the same. $\mathrm{M}_{\mathrm{F}}$ is extracted from the SQUID data. For $\mathrm{T}_{\text {init }} \leq 650 \mathrm{~K}, \mathrm{M}_{\mathrm{F}} \sim 1300 \mathrm{emu} \mathrm{cm} \mathrm{cm}^{-3}$ and it reduces to about $900 \mathrm{emu} \mathrm{cm}^{-3}$ for $\mathrm{T}_{\text {init }}=750 \mathrm{~K}$. Taking this into account for the explanation of the above ratio reduction, it implies that: (i) the higher the $\mathrm{T}_{\text {init }}$, the much larger the $\mathrm{J}_{\mathrm{F}-\mathrm{AF}}$; this is unlikely since layers intermixing usually results in less F-AF exchange bonds, which inversely reduces the effective $\mathrm{J}_{\mathrm{F}-\mathrm{AF}}$; or (ii) the product $\mathrm{J}_{\mathrm{AF}} \cdot \mathrm{M}_{\mathrm{AF}}$ drops, which is much more likely, as will be confirmed below. Additionally, it is noteworthy that, within the experimental error, the maximum values of $\mathrm{H}_{\mathrm{E}}$ and $\mathrm{H}_{\mathrm{C}}$, i.e., for $\mathrm{T}_{\mathrm{a}}=4 \mathrm{~K}$ in Fig. 2, are independent of $\mathrm{T}_{\text {init }}\left(\mathrm{H}_{\mathrm{E}} \sim 800 \mathrm{Oe}\right.$ and $\left.\mathrm{H}_{\mathrm{C}} \sim 250 \mathrm{Oe}\right)$ except for $\mathrm{T}_{\text {init }}=750 \mathrm{~K}$, for which $\mathrm{H}_{\mathrm{E}}$ reduces to $600 \mathrm{Oe}$ and $\mathrm{H}_{\mathrm{C}}$ rises to 600 Oe. $\mathrm{H}_{\mathrm{E}}$ relates to $\left(\mathrm{K}_{\mathrm{AF}} \cdot \mathrm{J}_{\mathrm{F}-\mathrm{AF}}\right)^{0.5} / \mathrm{M}_{\mathrm{F}}{ }^{6}{ }^{6}$ The thermally induced reduction of $\mathrm{H}_{\mathrm{E}}$ agrees with the aforementioned believed thermally induced reduction of $\mathrm{J}_{\mathrm{F}-\mathrm{AF}}$. It is likely accompanied by a decrease of $\mathrm{K}_{\mathrm{AF}}$ in order to counterbalance the measured drop of $\mathrm{M}_{\mathrm{F}}$. The rise of $\mathrm{H}_{\mathrm{C}}$ is consistent with reductions of $\mathrm{J}_{\mathrm{AF}} \cdot \mathrm{M}_{\mathrm{AF}}$ and $\mathrm{K}_{\mathrm{AF}}$, since they both lower $\mathrm{AF}$ phases' stability and the more sensitive AF phases consequently become persistently dragged by the $\mathrm{F}$.

Interestingly, the initial positive $\mathrm{FC}$ from 750 to $4 \mathrm{~K}$, when all the AF entities are oriented positively, leads to no training (see data point in Fig. 2 for $T_{\text {init }}=750 \mathrm{~K}$ and $\mathrm{T}_{\mathrm{a}}=4 \mathrm{~K}$ ). Conversely, the subsequent negative $\mathrm{FC}$ from 750 to $4 \mathrm{~K}$, when all the AF entities are reoriented negatively, (a)

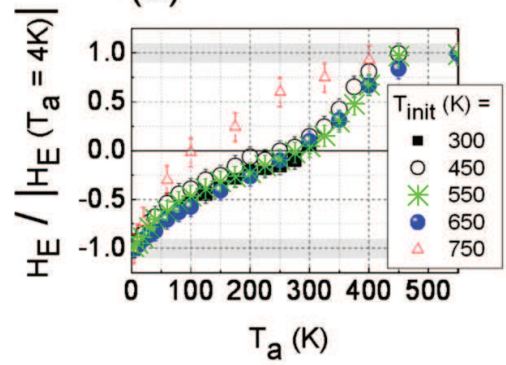

(b)

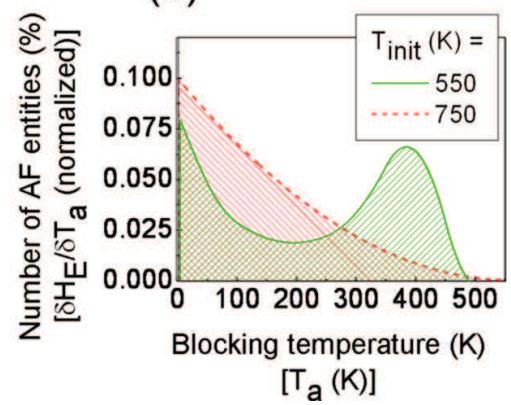

FIG. 4. (a) Comparison of the $\mathrm{H}_{\mathrm{E}} /\left|\mathrm{H}_{\mathrm{E}}\left(\mathrm{T}_{\mathrm{a}}=4 \mathrm{~K}\right)\right|$ vs $\mathrm{T}_{\mathrm{a}}$ variations deduced from Fig. 2. (b) Variations with $T_{a}$ of the corresponding normalized derivatives $\delta \mathrm{H}_{\mathrm{E}} / \delta \mathrm{T}_{\mathrm{a}}$ deduced from the full lines in Fig. 2 for $\mathrm{T}_{\text {init }}=550$ and $750 \mathrm{~K} . \delta \mathrm{H}_{\mathrm{E}} /$ $\delta \mathrm{T}_{\mathrm{a}}$ vs $\mathrm{T}_{\mathrm{a}}$ represent the blocking temperatures distributions, the integrals of which are set to $100 \%$. 
shows training (see data point for $\mathrm{T}_{\mathrm{a}}=750 \mathrm{~K}$ ). Although this discrepancy is not fully understood, it can be associated to the use of an $a b$ initio positive field which brings about a cause of asymmetry between the above data. It would then point out: (i) that the system tracks memory of the sign of the ab initio field; and (ii) that applying a field during deposition can prevent training effects, this latter being in all likelihood sufficient to initially set the $\mathrm{AF}$ in a deep enough energy potential well.

To compare the shapes of the $\mathrm{H}_{\mathrm{E}}$ vs Ta curves for the various $\mathrm{T}_{\text {init }}$, the variations are normalized to their maximum absolute value (for $\mathrm{T}_{\mathrm{a}}=4 \mathrm{~K}$ ) and plotted together in Fig. 4(a). Within error bars, the curves overlap for $\mathrm{T}_{\text {init }} \leq 650 \mathrm{~K}$, meaning that the low- $\mathrm{T}$ and high-T parts of $\mathrm{DT}_{\mathrm{B}}$ related to interfacial spin-glass and grains sizes distributions, respectively, are unchanged, whether the $\mathrm{Co} / \mathrm{IrMn}$ interface and the grains are as deposited (for $\mathrm{T}_{\text {init }}=300 \mathrm{~K}$ ) or annealed. Since $\mathrm{DT}_{\mathrm{B}}$ is very sensitive to changes of $\mathrm{F}$ and AF properties, ${ }^{5-16}$ one concludes that annealing $\mathrm{Co} / \mathrm{IrMn}$ bilayers up to slightly below $650 \mathrm{~K}$ neither significantly deteriorates the interface by adding more spin-glass phases subsequent to interdiffusions nor the grains by sizes and crystallographic changes. Although the overall shape of the $H_{E}$ vs $T_{a}$ curve is not significantly affected, it is noteworthy that the emergence of small training effects for $\mathrm{T}_{\text {init }}=650 \mathrm{~K}$ indicates premises of layers' modifications, which undeniably become manifest for $750 \mathrm{~K}$. Additionally, the discernible slight enhancement of the maximum $T_{B}$ for $\mathrm{T}_{\text {init }}=650 \mathrm{~K}$ may also well be real. This, as a plausible signature of a grains size increase due to larger $T_{\text {init }}$, cannot be excluded. References 9 and 11 agree that an increase of around $25 \mathrm{~K}$ of $\mathrm{T}_{\mathrm{B}}$ could result from an increase of around $2 \mathrm{~nm}$ of one of the grains' dimensions for typical grain diameters in the range of 5 to $10 \mathrm{~nm}$. Crystallographic changes, for example, leading to strain within grains cannot be discarded either as a possible cause of this potential increase. The derivatives of $\mathrm{H}_{\mathrm{E}}$ vs Ta represent the $\mathrm{DT}_{\mathrm{B}}$ (Refs. 7 and 9) and are plotted in Fig. 4(b) for $\mathrm{T}_{\text {init }}=550$ and $750 \mathrm{~K}$. The bimodal character of the derivative for $\mathrm{T}_{\text {init }}=550 \mathrm{~K}$ is characteristic of $\mathrm{T}_{\text {init }} \leq 650 \mathrm{~K}$. Interestingly, neglecting training effects by differentiating the $\mathrm{H}_{\mathrm{E}}$ vs $\mathrm{T}_{\mathrm{a}}$ variations deduced from 1st loops when there is training, e.g., for $\mathrm{T}_{\text {init }}=650$ and $750 \mathrm{~K}$, would lead to an overestimation of the low-T contribution due to spin-glass phases. It is additionally noticeable that the high-T contribution also exists for $\mathrm{T}_{\text {init }}=300 \mathrm{~K}$, since $\mathrm{H}_{\mathrm{E}}$ is due to reach back its maximum of around $800 \mathrm{Oe}$. However, the maximum pertinent value of $\mathrm{T}_{\mathrm{a}}$ is limited by $\mathrm{T}_{\text {init }}$, since above $\mathrm{T}_{\text {init }}$ effects due to $\mathrm{DT}_{\mathrm{B}}$ and annealing (when they occur) would mix up, hence making interpretations on $\mathrm{DT}_{\mathrm{B}}$ irrelevant. Figure 4(b) shows a clear change from bimodal to unimodal distribution. Only a broad contribution remains at $\mathrm{T}_{\text {init }}=750 \mathrm{~K}$, which can be ascribed to a shift towards lower $\mathrm{T}$ of the high-T contribution. This shift is in concurrence with the aforementioned reductions of AF properties, thus making AF grains sensitive to thermally activated reversal. Such a shift is possibly driven by a reduction of $\mathrm{K}_{\mathrm{AF}}$ and also by a decrease of $\mathrm{J}_{\mathrm{AF}} \cdot \mathrm{M}_{\mathrm{AF}}$ in the core of the grains, but to the extent that Eq. (1) is still fulfilled, since no training was observed for the grains.

To conclude, this study of the influence of annealing on the entire blocking temperature distributions of $\mathrm{Co} / \mathrm{IrMn}$ bilayers led to different responses, whether grains or spinglass-like phases were implicated. A better understanding of the respective contributions to $\mathrm{EB}$ of grains versus spin-glass was hence provided. Given the diversity of EB stacks and the subsequent large amount of thermally activated layers intermixing, there is a need for systematic comparisons of grains versus spin-glass contributions to EB for many more systems.

This work benefited from useful discussions with B. Dieny, H. Béa, L. Lechevallier, F. Letellier, R. Lardé, and J.-M. Le Breton. B. Dieny is also gratefully acknowledged for the critical reading of the manuscript.

${ }^{1}$ J. Nogués and I. K. Schuller, J. Magn. Magn. Mater. 192, 203 (1999).

${ }^{2}$ A. E. Berkowitz and K. Takano, J. Magn. Magn. Mater. 200, 552 (1999).

${ }^{3}$ B. Dieny, V. S. Speriosu, S. S. P. Parkin, B. A. Gurney, D. R. Wilhoit, and D. Mauri, Phys. Rev. B 43, 1297 (1991).

${ }^{4}$ W. H. Meiklejohn and C. P. Bean, Phys. Rev. 102, 1413 (1956).

${ }^{5}$ E. Fulcomer and S. H. Charap, J. Appl. Phys. 43, 4190 (1972).

${ }^{6}$ A. P. Malozemoff, Phys. Rev. B 35, 3679 (1987).

${ }^{7}$ S. Soeya, T. Imagawa, S. Mitsuoka, and S. Narishige, J. Appl. Phys. 76, 5356 (1994).

${ }^{8}$ V. Baltz, J. Sort, B. Rodmacq, B. Dieny, and S. Landis, Phys. Rev. B 72, 104419 (2005).

${ }^{9}$ V. Baltz, B. Rodmacq, A. Zarefy, L. Lechevallier, and B. Dieny, Phys. Rev. B 81, 052404 (2010).

${ }^{10}$ C. K. Safeer, M. Chamfrault, J. Allibe, C. Carretero, C. Deranlot, E. Jacquet, J.-F. Jacquot, M. Bibes, A. Barthélémy, B. Dieny, H. Béa, and V. Baltz, Appl. Phys. Lett. 100, 072402 (2012).

${ }^{11}$ K. O'Grady, L. E. Fernandez-Outon, and G. Vallejo-Fernandez, J. Magn. Magn. Mater. 322, 883 (2010).

${ }^{12}$ J. Ventura, J. P. Araujo, J. B. Sousa, A. Veloso, and P. P. Freitas, J. Appl. Phys. 101, 113901 (2007).

${ }^{13}$ K. Takano, R. H. Kodama, A. E. Berkowitz, W. Cao, and G. Thomas, Phys. Rev. Lett. 79, 1130 (1997)

${ }^{14}$ M. Ali, P. Adie, C. H. Marrows, D. Greig, B. J. Hickey, and R. L. Stamps, Nat. Mater. 6, 70 (2007).

${ }^{15}$ F.-T. Yuan, Y. D. Yao, S. F. Lee, and J. H. Hsu, J. Appl. Phys. 109, 07E148 (2011).

${ }^{16}$ A. G. Biternas, U. Nowak, and R. W. Chantrell, Phys. Rev. B 80, 134419 (2009).

${ }^{17}$ J. Nogués, J. Sort, V. Langlais, V. Skumryev, S. Surinach, J. S. Munoz, and M. D. Baro, Phys. Rep. 422, 65 (2005).

${ }^{18}$ M. Gruyters, Phys. Rev. Lett. 95, 077204 (2005).

${ }^{19}$ F. Letellier, V. Baltz, L. Lechevallier, R. Lardé, J.-F. Jacquot, B. Rodmacq, J.-M. Le Breton, and B. Dieny, J. Phys. D: Appl. Phys. 45, 275001 (2012).

${ }^{20}$ L. Lechevallier, A. Zarefy, F. Letellier, R. Lardé, D. Blavette, J. M. Le Breton, V. Baltz, B. Rodmacq, and B. Dieny, J. Appl. Phys. 112, 043904 (2012).

${ }^{21}$ L. Néel, Ann. Phys. (Paris) 2, 61 (1967).

${ }^{22}$ A. Hoffmann, Phys. Rev. Lett. 93, 097203 (2004).

${ }^{23}$ C. Binek, Phys. Rev. B 70, 014421 (2004).

${ }^{24}$ B. Beschoten, J. Keller, A. Tillmanns, and G. Güntherodt, IEEE Trans. Magn. 38, 2744 (2002). 